\title{
Low Power Embedded System Sensor Selection for Environmental Condition Monitoring in Supply Chain
}

Original Scientific Paper

\author{
Josip Zidar \\ J. J. Strossmayer University of Osijek, \\ Faculty of Electrical Engineering, Computer Science \\ and Information Technology Osijek \\ Cara Hadrijana 10b, Osijek, Croatia \\ josip.zidar@ferit.hr

\section{Tomislav Matić} \\ J. J. Strossmayer University of Osijek, \\ Faculty of Electrical Engineering, Computer Science \\ and Information Technology Osijek \\ Cara Hadrijana 10b, Osijek, Croatia \\ tomislav.matic1@ferit.hr
}

\author{
Ivan Aleksi \\ J. J. Strossmayer University of Osijek, \\ Faculty of Electrical Engineering, Computer Science \\ and Information Technology Osijek \\ Cara Hadrijana 10b, Osijek, Croatia \\ ivan.aleksi@ferit.hr

Filip Sušac
J. J. Strossmayer University of Osijek,
Faculty of Electrical Engineering, Computer Science
and Information Technology Osijek
Cara Hadrijana 10b, Osijek, Croatia
filip.susac@ferit.hr

\begin{abstract}
In the modern world different products and goods are available throughout the world thanks to the complex supply chain system. Often products are transported on long journeys with different transportation systems where products can be damaged or spoiled. Smart Sticker is a concept for product environmental condition monitoring that can resolve some problems in the supply chain. Smart Sticker will record product environmental data in the supply chain and enable producer/consumer product monitoring. Because of ultra-low power design, Smart Sticker component selection must satisfy ultra-low power specifications, besides standard accuracy, and real-time implementation. In this paper we give an overview of the necessary measured environmental parameters and the selection of sensors with emphasis on low power design. We provided a model for the calculation of the maximum operating time, which is applied for the two Smart Sticker instances with significantly different energy consumptions. In the worst-case scenario operation time is 198 days which can be increased with a higher capacity battery.
\end{abstract}

Keywords: low power, embedded system, sensor, supply chain, environmental condition monitoring

\section{INTRODUCTION}

Due to globalization, the supply chain has become a very complex process. It consists of several stages depending on the goods produced (frozen foods, fresh foods, electronic devices, etc.) and on the consumer that receives the goods. Transportation, warehousing, inventory, packaging, information, and control are the main elements of the supply chain, cf. Fig. 1. Depending on the type of goods and on the journey to the customer, different elements (e.g. goods can be transported multiple times via truck) can repeat multiple times [1], [2].

In the supply chain goods can get damaged because of different hazards. Most common hazards include spillage, shocks, vibrations, temperature change, accidents, handling, etc. Some of the hazards can be prevented with proper packaging, but this is not always true. Moreover, the type of goods influences the type of hazards. For vegetable commodities and products, spillage during transportation and degradation during handling are most common. Fish products are more prone to degradation during icing in the process of packaging, storage, and transportation, while for milk products spillage hazard is most common [3], [4].

In most of the stages of the supply chain information about the environmental conditions of the goods (temperature, humidity, vibration, etc.) is unknown, due to the complexity of the supply chain. This information can help in the reduction of the hazard probability, and therefore the reduction of the number of damaged goods. Additionally, it would be possible to detect the supply chain stage where the damage has occurred. If, for example, frozen food is transported from a producer to a consumer. On its journey, frozen food is stored 
in a chiller which sometimes fails to keep the required temperature. Because of this, some of the products become spoiled. In this example information about the environmental conditions would help to pinpoint the reason and possibly the location of the problem.

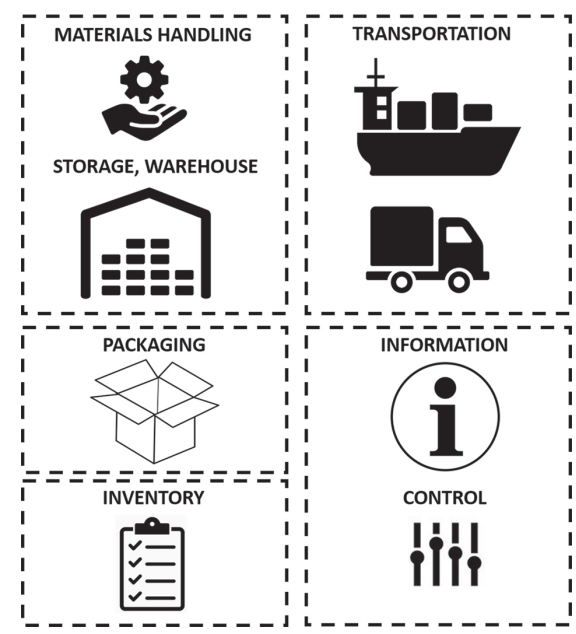

Fig. 1. Main components of the supply chain.

In [1] authors present a Smart Sticker concept that solves the problem of environmental conditions monitoring of goods in the supply chain. It is an ultra-low-power embedded device equipped with sensors for environmental conditions monitoring and RFID (Radio Frequency Identification) technology for data transfer. Device logs sensors data, date, and time which enable the consumer to track the environmental conditions of the received goods.
In this paper, parameters for the monitoring of the environmental conditions of goods in the supply chain are analyzed. The analysis is done based on the Smart Sticker concept and the suggestion from the local Croatian companies. Sensors are suggested to meet the required functionalities, with minimal power consumption. Minimal power consumption is necessary to enable long operation on battery during environmental conditions monitoring of the goods. The long battery life and the small size of the Smart Sticker ensure that it could be placed on a product or a pallet of products for monitoring. For such a device to be able to perform efficiently, it is necessary to analyze the limitations such as energy consumption, dimensions, and price. To measure proposed environmental conditions, state-of-the-art sensors are proposed, which use the latest manufacturing technologies and have the lowest energy consumption. Selected sensors are implemented on a Smart Sticker prototype shown in Fig. 2, and all presented measurements in this paper are done on the developed prototype. Additionally, power consumption is analyzed, and the total battery life of the Smart Sticker prototype is given based on two working scenarios.

The rest of this paper is organized as follows. Section 2 gives the literature overview of the paper topic. Detailed analysis of the monitoring parameters in the supply chain is given in Section 3. Proposed sensors setup and power analysis are outlined in Section 4. Finally, Section 5 concludes the paper by stating the drawn conclusions and providing remarks for future work.

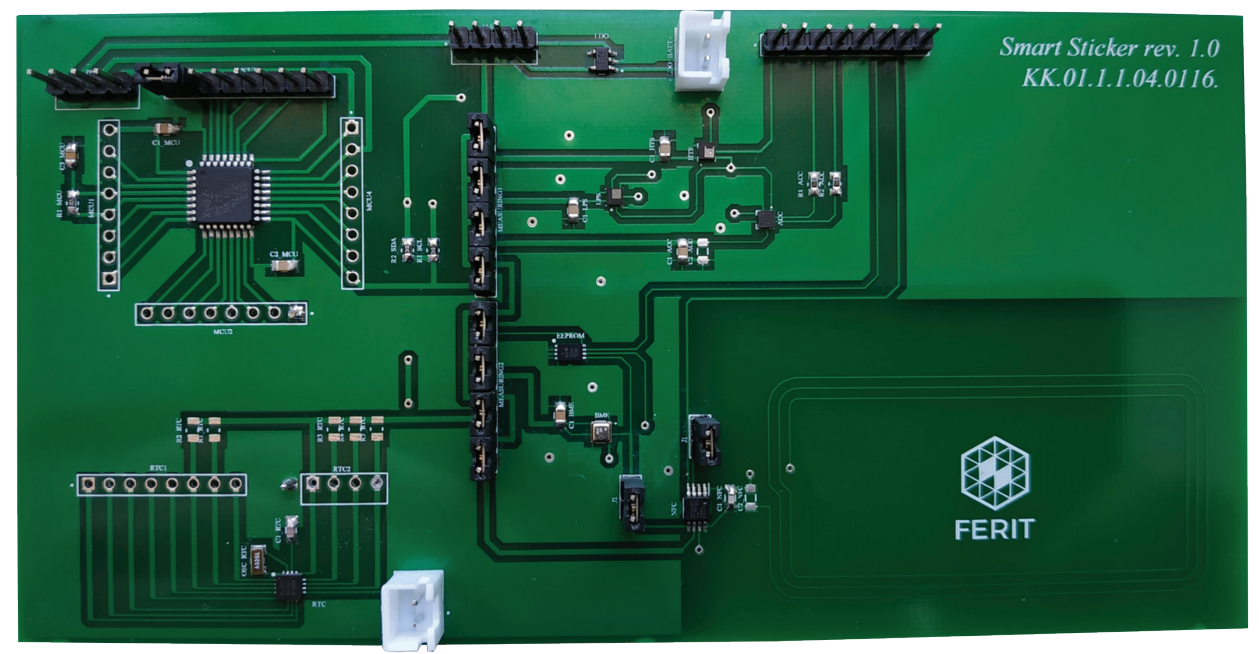

Fig. 2. The Smart Sticker prototype with the microcontroller (top-left), sensors (top-middle), EEPROM (center), NFC (bottom-right), and RTC (bottom-left).

\section{RELATED WORK}

There have been several attempts in resolving the problem of environmental conditions monitoring in the supply chain. Smart labels are one of the latest trends in emerging Industry 4.0, numerous prototypes of smart labels are presented and developed in the last decade. Nowadays, smart labels go beyond identification purposes, nor so- phisticated context-aware labels with embedded modules are currently state of the art [5]. Authors in [6] give a specification for an intelligent product as a part of the Auto-ID project. In the presented concept, goods can store data about themselves, and the ability to communicate with their environment. In the paper, the authors don't give any recommendation about the implementation of the intelligent product or the possible lifespan. 
In [7] authors present a system for real-time traceability and cold chain monitoring based on RFID technology. The developed tag is battery-powered and can measure light, temperature, and humidity. The authors used a CPLD device for low-power communication between sensors and a microcontroller. Device dimensions are relatively large and not convenient for easy implementation. Therefore, to achieve the IP65 protection standard, a large box is used. The system is tested on frozen fish products and it showed accurate measurements for temperature. The authors didn't give the maximum battery lifespan of the device and didn't analyze the power consumption under different working conditions or measurement scenarios. In [8] authors discuss traceability systems that will help in increasing the safety and the quality of food products. In the paper, several definitions of traceability are discussed, concentrated on the history, location, and data records of the food products. According to EU regulation (178/2002), traceability is the ability to trace and follow all stages of the supply chain. According to presented research, most papers and systems are focused on traceability until the retail point of the food chain, thereby the consumer part of the food chain is still not covered enough. All trends suggest that food traceability from "farm to fork" is going to become standard soon. In [9] authors present a start-up pilot project for food traceability based on passive RFID tags. Although the presented system detailed capture all stages of the supply chain no environmental conditions are considered at all.

In [10] authors present two typologies of the nondestructive electronic RFID-based tracking system with application in the cheese industry. During the cheese maturation process, only 4 measurements are acquired for 9 months period. Quality information, chemical, and spectrophotometric analysis are conducted with external systems and linked with the RFID identification tag placed on cheese and stored in a web-based application. From the customer's perspective, this system can be used only to validate the maturation process of cheese products. Information about storing, transporting, and other environmental conditions are not considered in this paper. In [11] RFID-based monitoring system for tracking fruit quality is presented. Flexible Tag Microlab (FTM) is communicating with fixed RFID reader AC powered equipped with gas sensors. Although this system reduces the costs of the tags themselves, all information acquired during monitoring is saved on an internal database and cannot be retrieved by the user. Active RIFD tags commonly lack long-life battery performance. To overcome this problem authors in [12] proposed a design for a self-powered RFID tag based on a piezoelectric power supply (PPS). According to their research using PPS integrated inside RFID temperature monitoring system, $0.283 \mathrm{~mW}$ of energy per 1 second can be generated during mobile transport of perishable items. For better monitoring and control of environmental conditions, authors in [13] present "Intelligent Container". The system where all transport conditions are measured inside the cargo box, which can help to control active devices such as air conditioners to maintain desired environmental conditions. This approach is useful to decrease food loss in the cold chain but no information about transport itself is available to the customer. With the emergence of printing technologies, new concepts are presented.

In [14] authors present an all-printed smart label with an integrated humidity sensor and power supply. Although the presented prototype can acquire environmental humidity no communication and data storage are integrated. In [15] authors present a different approach, a sensitive time-temperature indicator. A selfhealing nanofiber mat is devised that serves as a temperature sensor and a display. The proposed mat changes light transmittances with the temperature where the speed of the change can be regulated based on mat polymer composition and film thickness. The presented device cannot output or save the temperature data and therefore there is no traceability option. Similar devices are also presented in [16], [17]. In [18] authors present a smart RFID label with a printed multisensor platform. Using inkjet-printed technology multisensor platform for humidity, temperature, and ammonia is created. Evaluation of the presented platform confirms the possibility for commercial use of inkjet-printed sensors. Although sensors can achieve commercial standards, presented smart RFID labels with the one-hour interval between the measurements on $150 \mathrm{mAh}$ has an expected lifetime of only 57 days, which can't satisfy the requirement for mass scale usage. Another similar smart label based on flexible PCB (Printed Circuit Board) technology and self-created sensors is presented in [19]. As the presented prototype doesn't include internal storage, the expected battery life is not considered. Although information can be acquired using RFID technology, no information about the history of the environmental conditions is saved at all. Another smart label is presented in [20]. Using printed technology smart sticker for time-temperature history is presented, with a new $\mathrm{R} 2 \mathrm{R}$ printed battery proposed label's lifetime is up to 7 days, with one minute between each data logging. As the only temperature is considered, this approach is useful only for highly temperature-sensitive products such as fresh food, dairies, etc. Another RFID-based temperature monitoring system is presented in [21]. The presented system is designed in form of the biocompatible plaster using $130 \mathrm{~nm}$ CMOS technology, powered by a rechargeable lithium-ion battery. The system is used for constant body temperature monitoring in a hospital environment but the system itself can be applied to various temperature-sensitive processes. In [22] authors present a fully integrated passive UHF RFID tag for temperature environment monitoring. Using the energy of the incident RF signal from the base station, energy is converted to dc supply voltage and stored in capacitors, so the battery is not included in the design. In the active state, the total current dissipation of the proposed tag is $15.4 \mu \mathrm{A}$. The proposed design of the temperature sen- 
sor has a measuring error of $\pm 2{ }^{\circ} \mathrm{C}$, which is not sufficient for temperature-sensitive products. Although using RF signal to power tag is an effective approach, in lack of RF signal and no battery all monitoring data will be lost.

Considering all the afore mentioned, in this paper we consider commercially available sensors for low power embedded systems. Based on a created questionnaire, suppliers gave different parameters for environmental condition monitoring in the supply chain. Based on the acquired data, several sensors are presented that fulfill the set characteristics and can be implemented in Smart Sticker design. Final sensor selection is carried out based on the power analysis in different environmental conditions monitoring scenarios. Several Smart Sticker design instances are suggested, and the estimate of maximum time of system operation is given for different measurement sampling times.

\section{ENVIRONMENTAL CONDITION PARAMETERS}

Firstly, it is necessary to analyze the existing market and monitoring needs and propose a specified solution with selected sensors for environmental condition monitoring. The percentage of sold products in the EU by category is illustrated In Fig. 3. Other products include wood, paper, furniture, computers, electronic and optical products, textiles, wearing apparel, leather, pharmaceutical products, mining. The intended purpose of the Smart Sticker can be found in transport and storage in the food, pharmaceutical, chemical, electrical, and electronic engineering industries.
Damage to goods traveling from manufacturers to stores is a possible occurrence [3]. In the case of damaged electronics, defects can be detected even after the customer buys the product. This includes sensitive electronic devices, laptops, TVs, refrigerators, washing machines, etc. To reduce inconvenience to the buyer, seller, and the manufacturer, an environmental condition monitoring system is required. In this way, it would be possible to detect the supply chain stage where the damage has occurred. Other examples are in the frozen foods industry. After the freezing process, products are stored at $-18{ }^{\circ} \mathrm{C}$. Smart Sticker can monitor the storage temperature and it would be possible to detect when the product temperature changed above set threshold value. If the product is spoiled when the consumer buys it, the temperature history of the product can be traced and the supply stage located where the temperature hazard has occurred.

To analyze the need for a Smart Sticker system in practice, a questionnaire was sent to selected local companies. Selected companies have delivery and/ or production of goods as the main part of their business. In this way, the company can ensure quality in the production and/or delivery of goods or analyze deficiencies in the supply chain. The questionnaire sent included inquiries about general company information, a general description of the business model, a list of goods to be monitored in the supply chain, mode of transport, method of packaging, storage, and transport conditions, and required monitoring intervals.
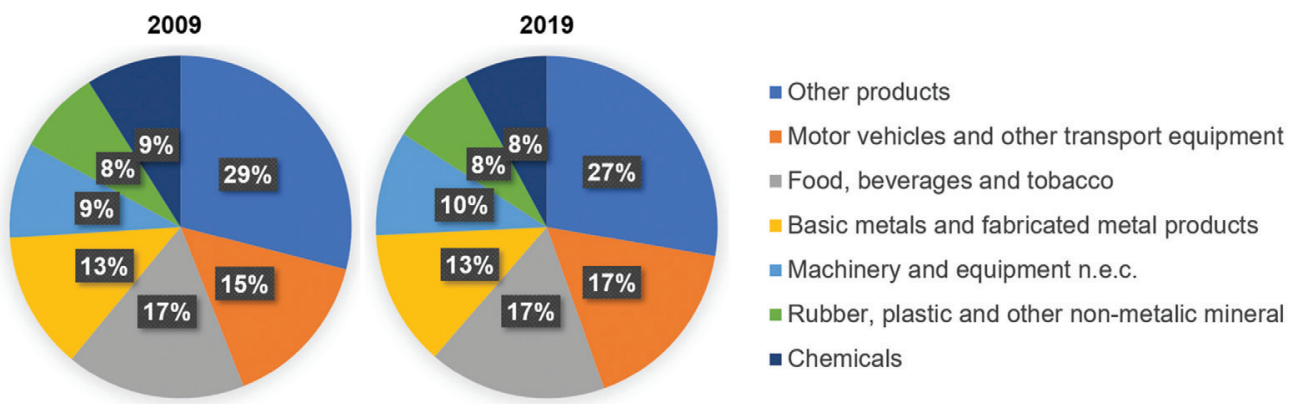

Fig. 3. Percentage of sold products for the years 2009 and 2019 in the EU

Table 1. Summarized questionnaire results from local companies

\begin{tabular}{|c|c|c|c|c|c|}
\hline Product type & Bakery & Meat & Meat & Fruit & Electrical \\
\hline Product name & Meat pie & Dry sausage & Burger & Apple & Cabinet \\
\hline Pieces per package & 55 & 7 & 8 & 78 & 1 \\
\hline Package size w/h/d [mm] & $291 / 256 / 212$ & $1200 / 800 / 725$ & $550 / 378 / 145$ & $600 / 400 / 180$ & $2000 / 1000 / 1000$ \\
\hline Packages per pallet & 84 & 30 & 40 & 48 & 1 \\
\hline Storage temperature $\{\min , \operatorname{typ}, \max \}\left[{ }^{\circ} \mathrm{C}\right]$ & $-25,-18,-17$ & $4,6,8$ & $4,6,8$ & $0,1,4$ & $-10,25,50$ \\
\hline Storage humidity $\{\min , \mathrm{typ}, \max \}[\%]$ & $0,50,95$ & $0,50,95$ & $0,50,95$ & $70,77,85$ & $0,50,95$ \\
\hline Sensitivity to vibrations & No & No & No & Yes & No \\
\hline Sampling period [hours] & 1 & 1 & 8 & 1 & 1 \\
\hline Storage duration [days] & 10 & 1 & 1 & 15 & 7 \\
\hline Transhipments during transport & 3 & 2 & 2 & 0 & 0 \\
\hline Transport duration [days] & 5 & 1 & 1 & 3 & 1 \\
\hline
\end{tabular}


Table 2. Low-power sensors which are considered in the design of an instance of the Smart Sticker

\begin{tabular}{|c|c|}
\hline Sensor ID & Measures \\
\hline Sensor 1 & Temperature and humidity \\
\hline Sensor 2 & Pressure \\
\hline Sensor 3 & Temperature, humidity and pressure \\
\hline Sensor 4 & Impact detection $5 \mathrm{~g}$ \\
\hline Sensor 5 & Impact detection $20 \mathrm{~g}$ \\
\hline Sensor 6 & Impact detection $60 \mathrm{~g}$ \\
\hline
\end{tabular}

Table 1 shows the main results of the questionnaire answered by local companies. To obtain more accurate data for Smart Sticker usage in practice, the results of questionnaires from companies are analyzed. Companies have expressed the need to monitor the temperature when transporting frozen foods that must be stored within a certain temperature range. Vibration sensitivity has also been a requirement, for companies transporting shock and vibration sensitive goods. According to the stated needs, the list of functional parts has been compiled and shown in Table 2 .

The exchange of data between the microcontroller and the peripheral units (sensors, NFC, RTC) is necessary, hence it is important to consider an appropriate low power communication protocol. Most of the peripheral devices support I2C (Inter-Integrated Circuit) and SPI (Serial Peripheral Interface) communication. SPI communication is more beneficial for applications that need a data stream, because of the full-duplex mode. Both $12 \mathrm{C}$ and SPI offer excellent integration when implementing communication between the microcontroller unit and peripherals with low data throughput requirements. I2C is more easily implemented for multiple device communication and has a smaller footprint on the PCB (only two wires are necessary) [23], [24]. In this paper, we use peripherals that support $\mathrm{I} 2 \mathrm{C}$ communication.

\section{SMART STICKER MODEL FOR THE BATTERY LIFE ESTIMATION}

The Smart Sticker device that is considered in this work has three modes: Sleep, Measure, and Transfer Mode, cf. Fig 4. It monitors environmental conditions over a long time, for a period of several months or even years, depending on the type of goods that are monitored. Using a battery as a power source the Smart Sticker significantly relies on a concept of low energy consumption. Subsequently, with reduced energy consumption, the space occupied by the battery also reduces. In this way, the Smart Sticker device is feasible in small dimensions and applies to products with small packaging in the product supply chain. Based on the measuring values, Smart Sticker comes in two proposed variants, Type A and Type B. Type A measures environmental conditions, while Type $B$ is used for impact and shock detection. To reduce the energy consumption and increase the maximum time of operation, the sensors are turned on periodically with a relatively long delay between the two measurement samples. The sampling time $t_{S}$ depends on the application and the dynamics of measured physical property. For example, a temperature sensor can have a much larger $t_{s}$ (Ionger delay between samples), while a vibration sensor requires a short $t_{S}$ due to the higher frequency of the measured signal. In this work, the following sampling time $t_{S}$ values are considered:

- once a minute,

- once every 10 minutes,

- once every 30 minutes,

- once an hour (60 minutes),

- once every 12 hours (720 minutes),

- once a day (1440 minutes),

- once a week (10080 minutes).

The Smart Sticker has three modes of operation: Measure Mode (MM), Sleep Mode (SM), and Transfer Mode (TM), cf. Fig 4. Each mode of operation has a specific energy consumption regime. During the MM, the microcontroller is communicating with the sensors which are measuring physical properties and are sending data via an $\mathrm{I} 2 \mathrm{C}$ communication protocol. The data is then stored in the EEPROM. During the SM, minimal energy is used by the Smart Sticker, only the RTC is consuming power from the battery. Finally, during the TM, the NFC device is providing the power for the MCU to read the data from the EEPROM.

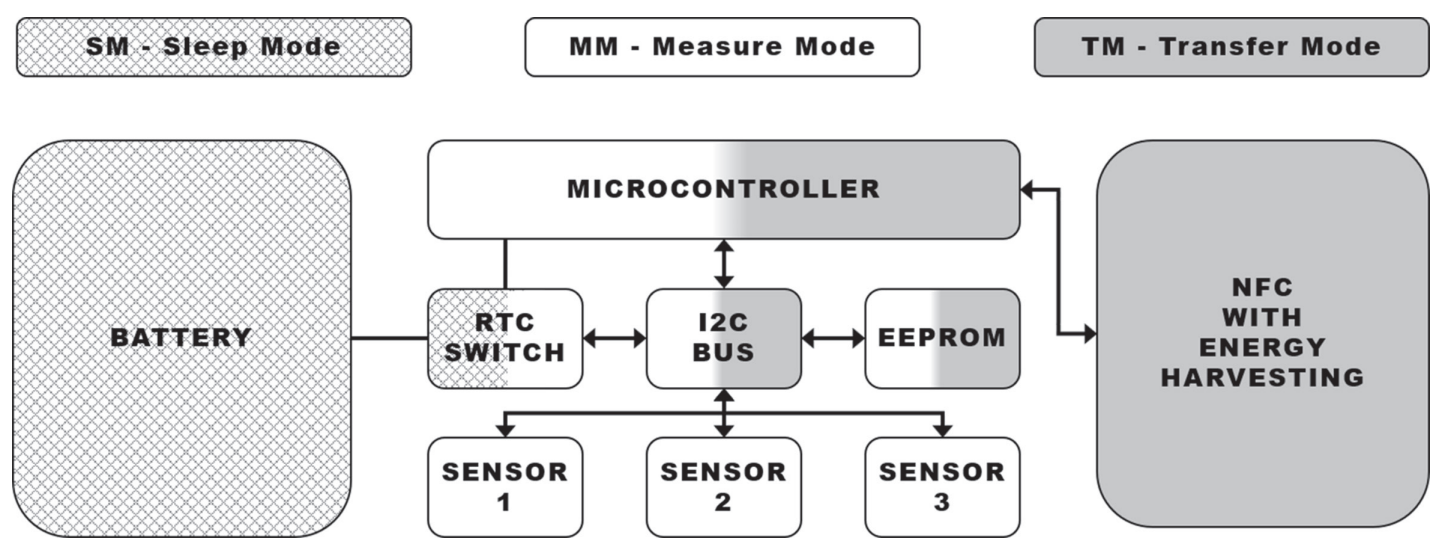

Fig. 4. The Smart Sticker design with three working modes. 
Integrated circuits used in the Smart Sticker design are selected from the set of devices with the smallest possible energy consumption on the market. The energy consumption of each component is measured, and it is illustrated in Table 3. Each measured value is obtained from an average of 100 measurements. For the measurements illustrated in Table 3, the Smart Sticker is powered with a $3 \mathrm{~V}$ CR2016 battery with $E_{B A T}=90 \mathrm{mAh}$. In this instance, the Smart Sticker has two temperature, humidity, and pressure sensors for redundancy reasons. Redundant sensors are only active in MM, thus having a very low impact on battery life. Additionally, in the case of redundant measurement of the same parameter, the memory requirement remains unchanged. After comparing measured redundant values with each other, only one parameter value is stored based on a voting procedure (e.g. two out of three voting).

Table 3. Current consumption of all components considered for an instance of the Smart Sticker.

$\begin{array}{cccc} & \text { I_MM }[\mu \mathrm{\mu A}] & \text { I_SM }[\mu \mathrm{A}] & \text { I_TM }[\mu \mathrm{A}] \\ \text { Sensor } 1 & 36.332 & 0.000 & 0 \\ \text { Sensor 2 } & 25.280 & 0.000 & 0 \\ \text { Sensor 3 } & 38.921 & 0.000 & 0 \\ \text { Sensor 4 } & 6.219 & 6.219 & 0 \\ \text { Sensor 5 } & 6.219 & 6.219 & 0 \\ \text { Sensor 6 } & 6.219 & 6.219 & 0 \\ \text { RTC } & 0.255 & 0.022 & 0 \\ \text { I2C } & 9.181 & 0.000 & 0 \\ \text { EEPROM } & 15.802 & 0.000 & 0 \\ \text { MCU } & 124.605 & 0.275 & 0\end{array}$

Further on, a calculation is done to estimate the maximum time of operation $t_{O P}$ of a Smart Sticker design instance. The calculation is done under the ideal room temperature conditions with $25^{\circ} \mathrm{C}$. The $t_{O P}$ is estimated by the measurements of the energy consumption of its components, the consumption of the battery selfdischarge, and the time when the components are consuming the energy at a certain operation mode MM, $\mathrm{SM}$, and TM, respectively.

The task of the Smart Sticker is to measure environmental conditions and utilize sleep function. With the measured energy consumption results in each mode of operation, the operating time can be calculated using

$$
\begin{aligned}
& t_{O P}=\frac{E_{B A T}}{I_{O P}} \\
& I_{O P}=\frac{I_{M M} \cdot t_{M M}+I_{S M} \cdot t_{S M}}{t_{S}}+t_{S} \cdot I_{S D}, \\
& t_{S}=t_{M M}+t_{S M}, \\
& I_{S D}=p_{S D} \cdot E_{B A T} .
\end{aligned}
$$

In equation (1), $E_{B A T}$ is the battery stored energy [Ah], and $I_{O P}$ is the total current $[\mu \mathrm{A}]$ consumed during the one sampling period $t_{S}$. During $t_{S^{\prime}}$ one MM and SM cycle is completed. The third operation mode, TM, is not considered in the equation since it is an asynchronous event, while SM and MM are repeating in cycles with period $t_{S}$. Additionally, in the TM mode, the Smart Sticker is powered from the RF field of the NFC chip and the onboard antenna. In Equation (2), sleep time $t_{S M}$ and measurement time $t_{M M}$ correspond to the operating modes $S M$ and $M M$, respectively. The sampling time $t_{S}$ is the sum of sleep and measure times, cf. eq. (3). Current consumptions in MM and SM are $I_{M M}$ and $I_{S M^{\prime}}$ respectively, cf. Table 3 . The self-discharge current $I_{S D}$ is calculated from the percentage $p_{S D}$ of discharge over the unit of time, which is usually expressed in percentage per month or percentage per year. Since $E_{B A T}$ is usually in [mAh], with hours as the unit of time, the $p_{S D}$ must be converted to the appropriate percentage per unit of time, for CR (Coin Manganese Dioxide Lithium

\begin{tabular}{|c|c|c|}
\hline & Value & Description \\
\hline$E_{B A T}$ & $90 \mathrm{mAh}$ & Battery capacity in mA hours \\
\hline$E_{B A T}$ & $5400000 \mu$ Amin & Battery capacity in $\mu \mathrm{A}$ minutes \\
\hline$E_{B A T}$ & $10.273 \mu$ Ayear & Battery capacity in $\mu \mathrm{A}$ years \\
\hline$p_{S D}$ & $1 \% /$ year & Battery self-discharge rate \\
\hline$t_{\text {BATSL }}$ & 10 years & Battery shelf life \\
\hline$I_{S D}$ & $0.103 \mu \mathrm{A} /$ year & $\begin{array}{l}\text { Self-discharge current in micro Amps per } \\
\text { year }\end{array}$ \\
\hline$I_{S D}$ & $\begin{array}{l}\text { 1.95E-07 } \mu \mathrm{A} \\
/ \mathrm{min}\end{array}$ & $\begin{array}{l}\text { Self-discharge current in micro Amps per } \\
\text { minute }\end{array}$ \\
\hline$t_{M M}$ & $0.017 \mathrm{~min}$ & $\begin{array}{l}\text { Time required to perform one measurement } \\
\text { cycle }\end{array}$ \\
\hline
\end{tabular}
Battery) battery $p_{S D}$ is $1 \%$ per year [25].

Table 4. Constant values used for calculations of estimated operation time.

\begin{tabular}{|c|c|c|c|c|c|}
\hline$\underset{[\mathrm{min}]}{t_{s}}$ & $\begin{array}{c}\boldsymbol{t}_{M M} \\
{[\mathrm{~min}]}\end{array}$ & $\begin{array}{c}\boldsymbol{t}_{S M} \\
{[\mathrm{~min}]}\end{array}$ & $\begin{array}{c}I_{S D} \\
{[\mu \mathrm{A}]}\end{array}$ & $\begin{array}{c}I_{O P} \\
{[\mu \mathrm{A}]}\end{array}$ & $\begin{array}{c}t_{o P} \\
{[y e a r]}\end{array}$ \\
\hline 1 & 0.017 & 0.983 & $1.95 \mathrm{E}-07$ & 4.195 & 2.45 \\
\hline 10 & 0.017 & 9.983 & $1.95 \mathrm{E}-06$ & 0.439 & $10(23.39)$ \\
\hline 30 & 0.017 & 29.983 & $5.86 \mathrm{E}-06$ & 0.161 & $10(63.78)$ \\
\hline 60 & 0.017 & 59.983 & $1.17 \mathrm{E}-05$ & 0.092 & 10 (112.23) \\
\hline 720 & 0.017 & 719.983 & $1.41 \mathrm{E}-04$ & 0.028 & $10(369.63)$ \\
\hline 1440 & 0.017 & 1439.983 & $2.81 \mathrm{E}-04$ & 0.025 & $10(412.65)$ \\
\hline 10080 & 0.017 & 10079.983 & $1.97 \mathrm{E}-03$ & 0.022 & $10(458.37)$ \\
\hline
\end{tabular}

Table 5. Estimated operation time of the Smart Sticker Type A with varying t_S sampling period.

Calculations using eq. (1) to (4) results with values illustrated in Table 5. Calculations predict the maximum operating time t_OP of the Smart Sticker device depending on the stored energy in the battery and on the energy consumption of used components. As can be seen, the maximum operating time t_OP is 10 years, due to battery shelf life t_BATSL. For a battery provided for a Smart Sticker, after 10 years it is assumed that the battery is no longer functional. 


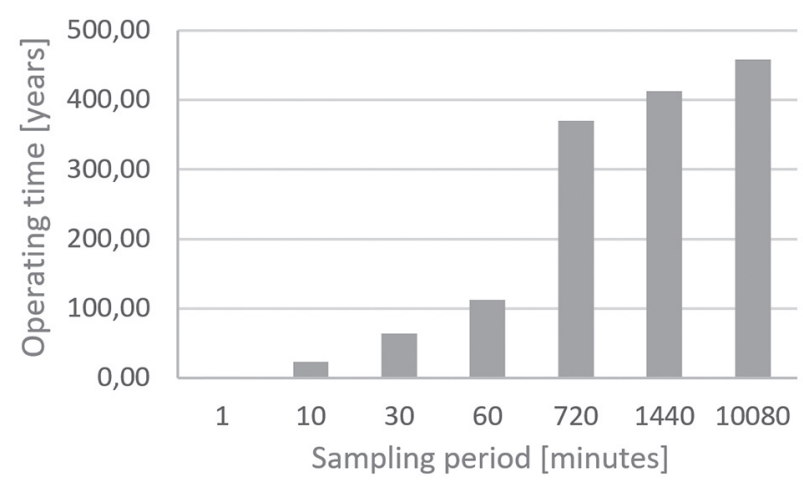

Fig. 5. Estimated operating time in dependence of the sampling period.

The estimated operation time of Smart Sticker Type $A$ is presented in Fig. 5 and Table 5, where Real-Time Clock (RTC) achieves significant energy savings using its alarm function to wake up the microcontroller periodically. RTC is the only working component in SM for Smart Sticker Type A.

As can be seen in Table 5, with more frequent measurements, i.e. with smaller sampling time, energy consumption increases. Increase in the energy consumption results with a shorter operating time, as it is shown in Fig. 5. Sampling period $t_{s}$ is a parameter that is adjustable by the user of the Smart Sticker, therefore it can vary depending on the application. Frequent measurements are usually preferred to achieve data continuity.

Furthermore, for detecting shocks and impacts during goods transportation and handling, Smart Sticker Type B is presented. Such detection must continuously check for the occurrence of a shock or impact, therefore consuming more energy in comparison to Smart Sticker Type A.

Table 6. Estimated operation time of the Smart Sticker instance types with $t_{s}=60$ minutes.

$\begin{array}{cccc}\text { Smart Sticker } & \boldsymbol{E}_{B A T}[\boldsymbol{\mu A y e a r}] & \boldsymbol{I}_{O P}[\boldsymbol{\mu A}] & \boldsymbol{t}_{O P}[\text { year] } \\ \text { Type A } & 10.273 & 0.092 & 10.00000 \\ \text { Type B } & & 18.932 & 0.54268\end{array}$

Impact detection is an event-based real-time system, where it is impossible to predict the number of times or when the shock or impact will occur in practice. When the Smart Sticker Type B registers a shock or an impact with its impact detection sensor, it wakes up from the SS to the MM to store the relevant data into the EEPROM. Subsequently, it goes back to the SM. The sensor for impact detections is continuously working in SM, while the MCU is in standby mode. In TM, impact detection data is transferred to the NFC device which provides the power for the microcontroller to read the stored data from the EEPROM, identical to TM in Smart Sticker Type A.

For estimating the operating time of Smart Sticker Type B, only SM calculations will be performed, be- cause it is impossible to predict an exact number of times when impact or shock will occur in practice and the device will enter MM. The estimated operation time for both Smart Sticker Type A and Type B is illustrated in Table 6. If we assume 1000 impacts per year $t_{O P}$ of Smart Sticker Type B will be 0.54254 years or 198 days which could be increased using a larger capacity battery. Depending on the need for impact or shock detection, specific threshold detection for certain products can be set. More sensitive (fragile) goods can have a lower threshold value, while less sensitive goods can have a higher threshold value. Damage of goods can vary for different products, which use different types of packaging materials and protection during transport.

\section{CONCLUSION}

The supply chain in the global world has become a very complex process. Goods on their journey from the producer to the customer go thru different supply chain stages, and can get damaged because of different hazards. Information about the environmental conditions of the goods in all stages of the supply chain can help in the reduction of the hazard probability and the detection of hazards.

In this paper we analyze the parameters for the monitoring of the environmental conditions of goods. Local suppliers answered a questionnaire about the environmental conditions of the produced goods. Based on the acquired answers several commercially available sensors are selected with low power operation. All sensors are implemented and tested on the Smart Sticker device.

Smart Sticker model for the battery life estimation is developed based on several parameters. Two Smart Sticker types are developed. Type A for environmental conditions monitoring and Type B for impact detection. Based on real-time measurements of the currents and different sampling times, operation time is estimated. In the worst-case scenario (sampling time $1 \mathrm{~min}$ ) for Type A, the estimated operation time is 2.45 years, and for Type B (1000 impacts per year) is 198 days.

Future work will include testing the prototypes in an industrial temperature and humidity chamber and on a vibration desk. Additionally, real-time measurements of the currents in different environmental conditions will be carried out. The aforementioned tests will help improve robustness for industrial applications. Finally, the developed prototype will be tested in real supply chain conditions where it can provide food safety and quality assurance.

\section{ACKNOWLEDGEMENT}

This work was funded by the European Union through the European Regional Development Fund, under project "Smart Sticker for measuring and monitoring storage and transportation conditions of products" KK.01.1.1.04.0116. 


\section{REFERENCES}

[1] F. Sušac, T. Matić, I. Vidović, I. Aleksi, and Ž. Hocenski, "Smart Sticker: Concept for Better Storage and Transportation", Proceedings of the 2020 International Conference on Smart Systems and Technologies, Osijek, Croatia, 14-16 October 2020, pp. 121-126.

[2] A. Rushton, P. Croucher, and P. Baker, "The handbook of logistics \& distribution management", $5^{\text {th }}$ Ed., Kogan Page, 2014.

[3] S. A. Alsobhi, K. K. Krishnan, D. Gupta, and A. T. Almaktoom, "Analysis of damage costs in supply chain systems", International Journal of Industrial and Systems Engineering, Vol. 28, No. 1, 2018, p. 70.

[4] J. Gustavsson, C. Cederberg, U. Sonesson, "Global food losses and food waste: extent, causes and prevention", Interpack 2011, Düsseldorf, Germany, 16-17 May 2011.

[5] T. M. Fernandez-Carames, P. Fraga-Lamas, "A Review on Human-Centered IoT-Connected Smart Labels for the Industry 4.0", IEEE Access, Vol. 6, 2018, pp. 25939-25957.

[6] C. Y. Wong, D. McFarlane, A. Ahmad Zaharudin, V. Agarwal, "The intelligent product driven supply chain", Proceedings of the IEEE International Conference on Systems, Man and Cybernetics, Yasmine Hammamet, Tunisia, 6-9 October 2002, pp. 1-6.

[7] E. Abad et al., "RFID smart tag for traceability and cold chain monitoring of foods: Demonstration in an intercontinental fresh fish logistic chain", Journal of Food Engineering, Vol. 93, No. 4, 2009, pp. 394-399, 2009.

[8] M. M. Aung, Y.S. Chang, "Traceability in a food supply chain: Safety and quality perspectives", Food Control, Vol. 39, 2014, pp. 172-184.

[9] I.-H. Hong et al., "An RFID application in the food supply chain: A case study of convenience stores in Taiwan", Journal of Food Engineering., Vol. 106, No. 2, 2011 pp. 119-126.

[10] P. Papetti, C. Costa, F. Antonucci, S. Figorilli, S. Solaini, P. Menesatti, “A RFID web-based infotracing system for the artisanal Italian cheese quality traceability", Food Control, Vol. 27, No. 1, 2012, pp. 234-241.
[11] A. Vergara et al., "An RFID reader with onboard sensing capability for monitoring fruit quality", Senssors and Actuators B: Chemical, Vol. 127, No. 1, 2007, pp. 143-149.

[12] H. Chu, G. Wu, J. Chen, F. Fei, J. D. Mai, W. J. Li, "Design and simulation of self-powered radio frequency identification (RFID) tags for mobile temperature monitoring", Science China Technological Sciences, Vol. 56, No. 1, 2013, pp. 1-7.

[13] R. Jedermann, T. Poetsch, W. Lang, "Smart Sensors for the Intelligent Container", Proceedings of the Smart SysTech 2014: European Conference on Smart Objects, Systems and Technologies, Dortmund, Germany, 1-2 July 2014, pp. 1-2.

[14] N. Pereira, V. Correia, N. Peřinka, C. M. Costa, and S. Lanceros-Méndez, "All-Printed Smart Label with Integrated Humidity Sensors and Power Supply", Advanced Engineering Materials, Vol. 23, No. 3, 2021.

[15] S. Choi et al., "A Self-Healing Nanofiber-Based SelfResponsive Time-Temperature Indicator for Securing a Cold-Supply Chain", Advanced Materials, Vol. 32, No. 11, 2020.

[16] A. Pavelková, "Time temperature indicators as devices intelligent packaging", Acta Universitatis Agriculturae et Silviculture Mendelianae Brunensis, Vol. 61, No. 1, 2013, pp. 245-251.

[17] H. Vaikousi, C. G. Biliaderis, K. P. Koutsoumanis, "Applicability of a microbial Time Temperature Indicator (TTI) for monitoring spoilage of modified atmosphere packed minced meat", International Journal of Food Microbiology, Vol. 133, No. 3, 2009, pp. 272-278.

[18] A. V. Quintero et al.,"Smart RFID label with a printed multisensor platform for environmental monitoring", Flexible and Printed Electronics, Vol. 1, No. 2, 2016.

[19] E. Smits et al., "Development of printed RFID sensor tags for smart food packaging", Proceedings of the IMCS, Nuremberg, Germany, 20-23 May 2012, pp. 403-406.

[20] B. B. Maskey et al., "A Smart Food Label Utilizing Rollto-Roll Gravure Printed NFC Antenna and Thermistor to Replace Existing "Use-By" Date System", IEEE Sensors Journal, Vol. 20, No. 4, 2020, pp. 2106-2116. 
[21] C. Kollegger, C. Steffan, P. Greiner, M. Wiessflecker, G. Holweg, and B. Deutschmann, "Intelligent plaster for accurate body temperature monitoring and investigations regarding EMI using near-field magnetic scan", Elektrotechnik und Informationstechnik, Vol. 133, No. 1, 2016, pp. 25-31.

[22] Hongwei Shen, Lilan Li, Yumei Zhou, "Fully integrated passive UHF RFID tag with temperature sensor for environment monitoring", Proceedings of the $7^{\text {th }}$ International Conference on ASIC, Guilin, China, 22-25 October 2007, pp. 360-363.

[23] A. Gloria, F. Cercas, N. Souto, "Comparison of communication protocols for low cost Internet of Things devices", Proceedings of the South Eastern
European Design Automation, Computer Engineering, Computer Networks and Social Media Conference, Kastoria, Westen Macedonia, 23-25 September 2017, pp. 1-6.

[24] A. K. Oudjida, M. L. Berrandjia, R. Tiar, A. Liacha, K. Tahraoui, "FPGA implementation of I ${ }^{2}$ C \& SPI protocols: A comparative study", Proceedings of the $16^{\text {th }}$ IEEE International Conference on Electronics, Circuits and Systems, Yasmine Hammamet, Tunisia, 13-16 December 2009, pp. 507-510.

[25] muRATA, "Coin Manganese Dioxide Lithium Battery Technical note", https://www.mouser.com/ pdfDocs/tcn-cr-001-200722-2.pdf (accessed: 2021) 